\title{
ESTIMATION OF VALUE OF TIME OF TOLL ROAD USERS IN INDIA
}

\author{
Rajorshi Sen Gupta ${ }^{1}$, Mohammed Anjal ${ }^{2}$ \\ ${ }^{1,2}$ Department of Economics, BITS Pilani KK Birla Goa Campus, India \\ ${ }^{2}$ Department of Computer Science, BITS Pilani KK Birla Goa Campus, India
}

Received 3 July 2020; accepted 17 August 2020

\begin{abstract}
Toll road projects in India have been facing the problem of overestimated revenue forecasts. Given the importance of toll road users' value of time (VOT) and consequently willingness to pay (WTP) on expected toll revenue, there is dearth of information regarding VOT of toll road users in India. This paper addresses this important gap in literature by providing a methodology to estimate VOT in the absence of primary survey data. Using 74 origin-destination pairs involving a toll road and an alternative non-tolled road, a unique database was prepared to estimate travel time saved (TTS) and VOT of seven different user categories of vehicles. Each of the seven user categories are found to be characterized by different VOT. The user heterogeneity in terms of VOT is an important finding which needs to be accounted for while conducting revenue estimates and economic feasibility analysis of proposed toll roads. Moreover, point estimates of VOT have limited application in conducting toll road feasibility analysis. Using stochastic TTS data, it is found that VOT of different user categories follow LogNormal distribution(s). The estimated projections on VOT can prove to be useful in improving the toll revenue forecasting in the context of India. The methodology can also be applied to other developing countries in the absence of primary data on VOT and WTP of potential toll road users.
\end{abstract}

Keywords: value of time, willingness to pay, travel time saving, toll road.

\section{Introduction}

India is increasingly relying on private sector financing of infrastructure projects like toll road development. In a developing country where there is limited number of toll roads, the economic appraisal of potential toll roads becomes a daunting exercise. Traffic revenue risk has indeed become a serious concern for several toll roads in India (Singh and Kalidindi, 2006).

In the recent years, most of the national and express highway projects in India are built on the basis of private-public partnership (PPP) model. But in most of these cases there is severe mismatch between the estimated and actual toll revenue collection. For instance, the daily toll collection on Mumbai-Surat road was $40 \%$ below projections in first year of operation. Fitch Ratings India had indicated systematic traffic volume overestimation on some highways (Seetharaman, 2012). Out of the ten operational projects discussed in the report; four had first-year traffic that is more than $35 \%$ below estimates. In case of Komarapalayam-Chengapalli road

${ }^{1}$ Corresponding author: rajorshis@goa.bits-pilani.ac.in 
(Tamil Nadu), during its first full year of operation the average daily toll collection was more than $40 \%$ below estimates. In the case of Bandra-Worli sea-link, during 2009-2018, only Rs 620 crores have been collected as toll against the estimated Rs 1240 crores. Evidently such traffic and revenue overestimates lead to increased risk for potential financiers and stakeholders. Given that most of the toll roads in India are Build-Operate-Transfer (BOT) type, precise estimate of toll revenue has become a critical requirement. Build-operate-transfer (BOT) has emerged to be one of the preferred models of public-private partnership (PPP) for attracting private capital in the Indian highway sector. In such $\mathrm{BOT}$ projects the traffic demand is considered a critical risk (Iyer and Sagheer, 2011).

Indian Road Congress (IRC, 2009) has recommended a standard methodology for the calculation of estimated toll revenue. The existing methodology typically takes into account various factors like operating costs, wholesale price index (WPI), regional economic growth rates, among other factors. This method has been used as a guideline for the revenue forecasts in most of the studies in India. It is important to note that the forecasts using that standard methodology were found to be over-estimated in comparison to the actual toll collection.

This leads to an important question: what leads to such overestimated revenue forecasts for toll roads? While revenue projections depend on various factors, one of the most critical factors is willingness to pay (WTP) of the potential users of a toll road. It is critically important to have proper information regarding the WTP among potential users. In the absence of proper estimates of users' WTP, the estimated toll revenue would likely to be erroneous.

WTP for tolls, in turn, depends on Value of Time (VOT) of the potential users. Essentially, VOT captures the tradeoff between time and money (Brownstone and Small, 2005; Small, 2012). Erroneous assumptions and estimates of VOT lead to adverse effect on revenue estimates (Gupta and Vadali, 2008). Eventually this leads to wrong predictions about economic feasibility of proposed toll roads. In the absence of reliable data, consultants and analysts may end up with overestimated VOT and hence over optimistic revenue estimates. Travel demand forecasting models often lead to overestimated demand for tolled facilities. This can occur when analysts overestimate VOT of toll road users.

Unfortunately, the data on VOT and WTP are either unavailable or sparse in the context of India. For this paper, a comprehensive study has been undertaken to calculate the VOT of various categories of users for toll roads under the National Highway Authority of India (NHAI).

\section{Literature Review}

A review of the international literature indicates the nature and severity of the problem of toll road forecasts. Bain (2009) analyzed a database of predicted and actual traffic usage for over 100 international, privately financed toll road projects. $\mathrm{He}$ found considerable optimism bias in toll revenue forecasts.

As pointed out by Hensher (2001), the value of travel time savings (VTTS) is a critical parameter in transport project appraisal. The current practice of forecasting the demand for new tolled roads typically assumes that 
car users are prepared to pay a higher toll for a shorter journey, and they will keep doing so as long as the toll cost is not higher than their current value of travel time savings (Hensher et al., 2016). They also found that ignoring the toll saturation effect is likely to result in an upward prediction of toll road patronage. Hensher and Goodwin (2004) pointed out that when an average value is taken as representative of a skewed distribution of values, there will be a tendency to overestimate the revenue, and underestimate the traffic impact, of a charge, because for a given mean VTTS, there will be a smaller number of individuals who are prepared to pay the toll.

Yang et al. (2002) examined the impact of user heterogeneity on the profitability and social welfare aspects of new toll roads. Boyer (1997) and Kawamura (2003) illustrated the importance of heterogeneity in the value of time (VOT) in the context of congestion pricing. Recent studies indicate that there is significant heterogeneity in preferences and values of time among drivers (Toledo and Sharif, 2019). Less traffic than expected and low toll revenue from the construction of transportation infrastructure projects lead to business failure ( $\mathrm{Ku}$ and $\mathrm{An}, 2020)$. In India, the revenue and toll forecasts are done by using the Vehicle operating cost (VOC) and value of passenger time (VPT) parameters as proposed by the Indian Road Congress (IRC, 2009). VOC includes the maintenance cost and fuel cost of vehicles (IRC, 2009). The IRC calculates the revenue of any toll road based on the expected traffic on the toll road from three categories: diverted traffic from the alternative roads, new traffic initiated due to new road and new traffic initiated because of the development activities due to the new road. Around $80 \%$ of the traffic in the initial years would be from the first category (IRC, 2009) which is highly dependent on the WTP. Nevertheless, overestimated WTP would lead to wrong assessment of diverted traffic, which in turn would lead to overestimated toll revenue. In the traffic and toll revenue analysis on Vadodara Express Highway, the analysts considered the VOT values provided by the IRC manual and the values have simply been inflated using the available WPI (IIDC, 2015). According to the revenue forecast of the Purvanchal express highway, VOT has been omitted from the calculation and instead Value of Passenger Time (VPT) has been used (IIDC, 2015). Since the VPT does not take into consideration the travel time saved (TTS), this variable cannot be used to estimate WTP of toll road users.

Based on the studies discussed above, it has been observed that the VOT of users has been either ignored or included vaguely while conducting toll revenue forecasts in India. Bagui and Ghosh (2012), for instance, analyzed traffic and revenue risk of a BOT project without considering VOT of the users. In contrast, the studies based on developed countries routinely include appropriate measures of VOT while estimating WTP and toll revenue forecasts (NCHRP, 2006).

Given the importance of VOT and WTP, unfortunately there is lack of reliable information on VOT of toll road users in India. Moreover, existing studies have been conducted at highly localised level. 
Among the very few studies, Athira et al. (2016) estimated VOT for work trips in the city of Calicut, Kerala and found variation of VOT by income group of travellers. In developed countries, primary data intensive estimation of travel choice models is widely deployed to estimate VOT (Ben-Akiva et al., 1993). In a developing country like India, passenger travel time savings are often not considered while conducting economic feasibility analysis (IRC, 2009). Therefore a timely study is warranted to estimate VOT of toll road users in India.

Thus the research questions of this paper are: What is VOT of different user categories of toll roads in India? Moreover, how to estimate VOT of different user categories in the absence of primary survey data? Finally, what can be said about the distribution of VOT across the various user categories?

\section{Data Source}

The National Highway Authority of India (NHAI) maintains a database including the origin and destination information and toll charges collected at various toll booths (NHAI, 2020). This portal has been the primary data source for all the toll roads included in the present study. Many of the toll roads have multiple toll booths; consequently, the sum of all the toll rates between two locations has been used. For each of these source-destination pair, an alternative "free route" that doesn't have toll charges is also identified. In general, the toll roads are expected to involve less time than the free alternative route. The alternative "free routes" were obtained by using the Google Maps software.

Based on the available (cleaned) data, a total of 74 origin-destination pairs are included in the final analysis. The travel time data on toll road and the alternative route were collected from Google Maps, which provides real time GPS forecasted data. Data were collected at four different time periods of a day: $6 \mathrm{AM}$, $10 \mathrm{AM}, 6 \mathrm{PM}$ and $10 \mathrm{PM}$. This exercise was repeated for one week and average travel time(s) were calculated for each of the four time periods.

For the study, seven different categories of vehicles were included: a) Light Passenger Vehicles (LPV); b) Light Commercial Vehicles (LCV); c) Buses/Trucks; d) Upto 3 Axle Vehicles; e) 4 to 6 Axle Vehicles; f) 7 or More Axle Vehicles; and g) Heavy Construction Machinery (HCM) / Earth Moving Equipment.

Finally, the data on toll rate $\tau_{i}$ for each of the $i^{\text {th }}$ user category are collected from National Highway of India website (NHAI, 2020).

\section{Methodology}

The travel time data provided by Google Maps is relevant for passenger cars. Consequently the travel time for each category of vehicle was obtained by using the following equation: 
The travel speed data for each category of vehicles were collected from Ministry of Road Transport and Highways (MORTH, 2020). In the next step the Travel Time Saved (TTS) were calculated. For each of the 74 origindestination pairs, suppose the estimated time to travel through the tolled route is $\mathrm{T} 2$ and the estimated travel time through the alternative "free" route be T1. Consequently the TTS is calculated as follows:

$T T S=T 2-T 1=\Delta T$

Given the research objective of estimating VOT, it is important to include the stochastic TTS in the estimation process. Simulation software Simetar ${ }^{\circledR}$ is used to estimate TTS by using Empirical Distribution. Based on the data obtained at four different time periods, the Empirical distribution incorporated the stochastic nature of TTS.

It is important to note that while TTS varies over different points of time throughout the day, the toll rate $\tau_{i}$ is specific to the $i^{\text {th }}$ user category and does not vary by time. Thus dynamic pricing is not prevalent in the Indian toll roads. Consequently, the implicit Value of Time (VOT) for each user category $i$ is estimated by using the following equation:

$\operatorname{VOT}_{i}\left(\frac{R s}{\text { hour }}\right)=\frac{\tau_{i}(R s)}{\Delta T(\text { minutes })} \times 60$

\section{Results}

The summary statistics of Travel Time Saved (TTS) are provided below:

\section{Table 1}

Travel Time Saved (TTS) in Minutes

\begin{tabular}{|c|c|c|c|c|c|}
\hline & $\begin{array}{c}\text { TTS } \\
\text { at 6AM }\end{array}$ & $\begin{array}{c}\text { TTS } \\
\text { at 10AM }\end{array}$ & $\begin{array}{c}\text { TTS } \\
\text { at 6PM }\end{array}$ & $\begin{array}{c}\text { TTS } \\
\text { at 10PM }\end{array}$ & $\begin{array}{c}\text { TTS using } \\
\text { Empirical Distribution }\end{array}$ \\
\hline Mean & 36.4 & 40.9 & 35.6 & 34.4 & 36.6 \\
\hline SD & 29.9 & 34.5 & 28.0 & 26.4 & 27.8 \\
\hline Min & 2.0 & 4.0 & 4.0 & 4.0 & 4.6 \\
\hline Median & 25.0 & 26.0 & 25.0 & 25.5 & 26.8 \\
\hline Max & 153.0 & 148.0 & 147.0 & 136.0 & 144.6 \\
\hline
\end{tabular}

Source: Methodology as described in Eq. 2

Employing Eq. 3, the Empirical TTS values along with the toll rates are used to calculate the VOT of the sever user categories. The summary statistics of thus obtained VOT are presented in Table 2 .

As observed in Table 2, the VOT values differ according to categories of the vehicles. Thus, each category of vehicle will be characterized by different WTP for tolls.

This user heterogeneity in terms of VOT is an essential factor that needs to be considered while conducting revenue estimates and economic feasibility analysis of proposed toll roads. 
Table 2

Value of Time (VOT) of Toll Road Users in Indian Rupees (Euro)/ Hour

\begin{tabular}{|l|c|c|c|c|c|c|c|}
\hline & $\begin{array}{c}\text { Light } \\
\text { Passenger } \\
\text { Vehicles } \\
\text { (LPV) }\end{array}$ & $\begin{array}{c}\text { Light } \\
\text { Commercial } \\
\text { Vehicles } \\
(\mathbf{L C V})\end{array}$ & $\begin{array}{c}\text { Buses/ } \\
\text { Trucks }\end{array}$ & $\begin{array}{c}\text { Upto 3 Axle } \\
\text { Vehicles }\end{array}$ & $\begin{array}{c}\text { 4 to 6 Axle } \\
\text { Vehicles }\end{array}$ & $\begin{array}{c}\text { Heavy } \\
\text { 7 or More } \\
\text { Axle } \\
\text { Vehicles }\end{array}$ & $\begin{array}{c}\text { Construction } \\
\text { Machinery } \\
\text { (HCM) } \\
\text { Earth Moving } \\
\text { Equipment }\end{array}$ \\
\hline Mean & 273.3 & 478.7 & 984.2 & 1353.4 & 1545.1 & 1785.3 & 1582.8 \\
Euro/hour & 3.11 & 5.44 & 11.18 & 15.38 & 17.56 & 20.29 & 17.99 \\
\hline SD & 194.7 & 374.6 & 772 & 991.8 & 1214 & 1438 & 1222.8 \\
Euro/hour & 2.21 & 4.26 & 8.77 & 11.27 & 13.80 & 16.34 & 13.90 \\
\hline 95\% LCI & 221.5 & 379.1 & 778.9 & 1089.6 & 1222.2 & 1402.8 & 1257.6 \\
Euro/hour & 2.52 & 4.31 & 8.85 & 12.38 & 13.89 & 15.94 & 14.29 \\
\hline 95\% UCI & 325.1 & 578.3 & 1189.6 & 1617.2 & 1868 & 2167.7 & 1908 \\
Euro/hour & 3.69 & 6.57 & 13.52 & 18.38 & 21.23 & 24.63 & 21.68 \\
\hline Min & 57.1 & 100 & 200 & 246.4 & 246.4 & 246.4 & 246.4 \\
Euro/hour & 0.65 & 1.14 & 2.27 & 2.80 & 2.80 & 2.80 & 2.80 \\
\hline Median & 217.5 & 381.6 & 791 & 1070.1 & 1248.8 & 1485.6 & 1276.2 \\
Euro/hour & 2.47 & 4.34 & 8.99 & 12.16 & 14.19 & 16.88 & 14.50 \\
\hline Max & 1071.4 & 2163.2 & 4515.8 & 5242.1 & 7089.5 & 8415.8 & 7089.5 \\
Euro/hour & 12.18 & 24.58 & 51.32 & 59.57 & 80.56 & 95.63 & 80.56 \\
\hline Skewness & 2.2 & 2.5 & 2.5 & 1.9 & 2.5 & 2.6 & 2.4 \\
Euro/hour & 0.025 & 0.028 & 0.028 & 0.022 & 0.028 & 0.030 & 0.027 \\
\hline Kurtosis & 5.7 & 6.9 & 7.4 & 4.1 & 7.3 & 7.9 & 6.7 \\
Euro/hour & 0.065 & 0.078 & 0.084 & 0.047 & 0.083 & 0.090 & 0.076 \\
\hline
\end{tabular}

Source: Methodology as described in Eq. 3

Equivalent values are computed by using the Exchange rate of 1 Euro $=88$ Indian Rupees in 2020

The Boxplots of the VOT distributions are presented in Fig. 1. It is found that all the distributions are positively (right) skewed. The histograms of the VOT distributions by different user categories are presented in Fig. 2 to Fig. 7. Based on further probe, it has been found that the VOT of different user categories follow Log-Normal distribution(s). The parameter estimates are presented in Table 3.

Table 3

Log-Normal Parameter Estimates of Value of Time (VOT) of Different Toll Road User Categories

\begin{tabular}{|c|c|c|c|c|c|c|c|}
\hline Parameter & $\begin{array}{c}\text { Light } \\
\text { Passenger } \\
\text { Vehicles } \\
(\mathbf{L P V})\end{array}$ & $\begin{array}{c}\text { Light } \\
\text { Commercial } \\
\text { Vehicles } \\
(\mathbf{L C V})\end{array}$ & $\begin{array}{c}\text { Buses/ } \\
\text { Trucks }\end{array}$ & $\begin{array}{c}\text { Upto 3 Axle } \\
\text { Vehicles }\end{array}$ & $\begin{array}{c}\text { 4 to 6 Axle } \\
\text { Vehicles }\end{array}$ & $\begin{array}{c}\text { Heavy } \\
\text { or More } \\
\text { Axle } \\
\text { Vehicles }\end{array}$ & $\begin{array}{c}\text { Construction } \\
\text { Machinery } \\
\text { (HCM) / } \\
\text { Earth Moving } \\
\text { Equipment }\end{array}$ \\
\hline$\mu$ & 5.43 & 5.96 & 6.69 & 7.00 & 7.13 & 7.26 & 7.15 \\
\hline$\sigma$ & 0.59 & 0.62 & 0.61 & 0.65 & 0.64 & 0.66 & 0.65 \\
\hline
\end{tabular}




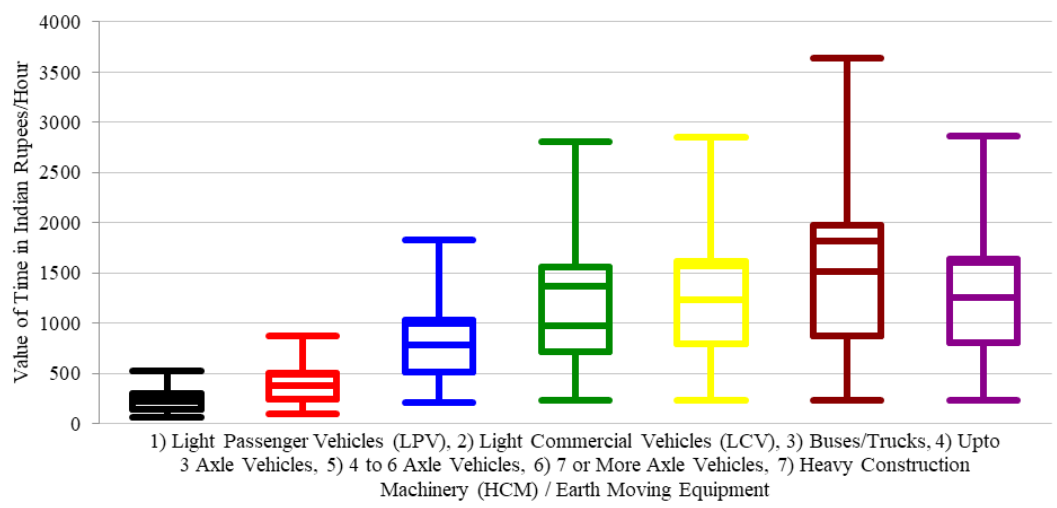

Fig. 1.

Boxplots of Value of Time of Different user Categories in Indian Rupees/Hour

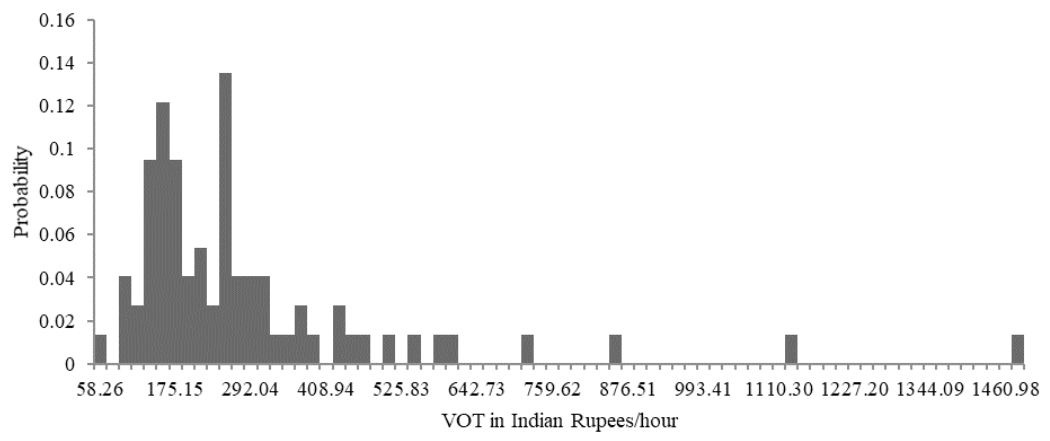

Fig. 2.

Histogram of VOT of Light Passenger Vehicles

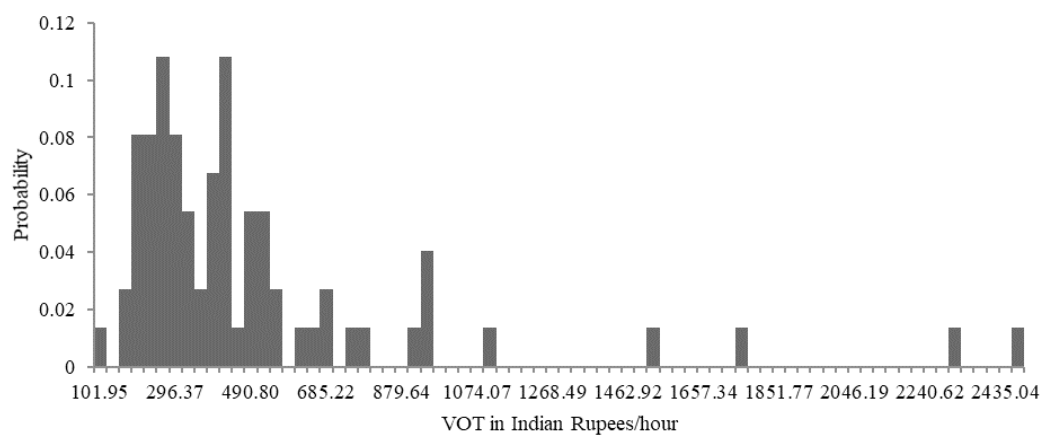

Fig. 3.

Histogram of VOT of Light Commercial Vehicles 


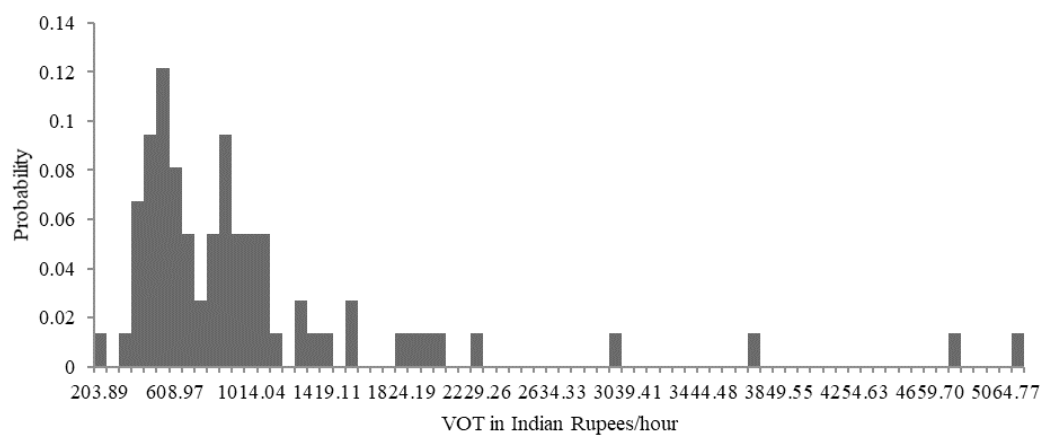

Fig. 4.

Histogram of VOT of Buses / Trucks

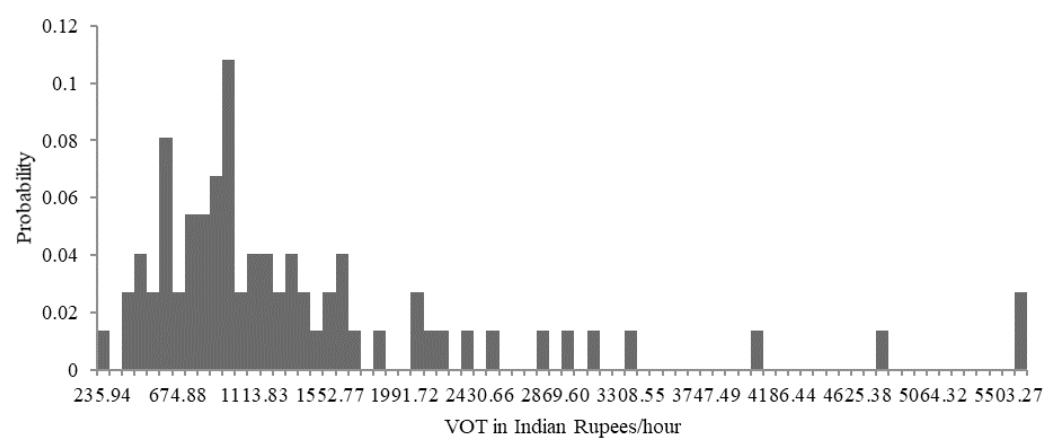

Fig. 5.

Histogram of VOT of Vehicles up to 3 Axles

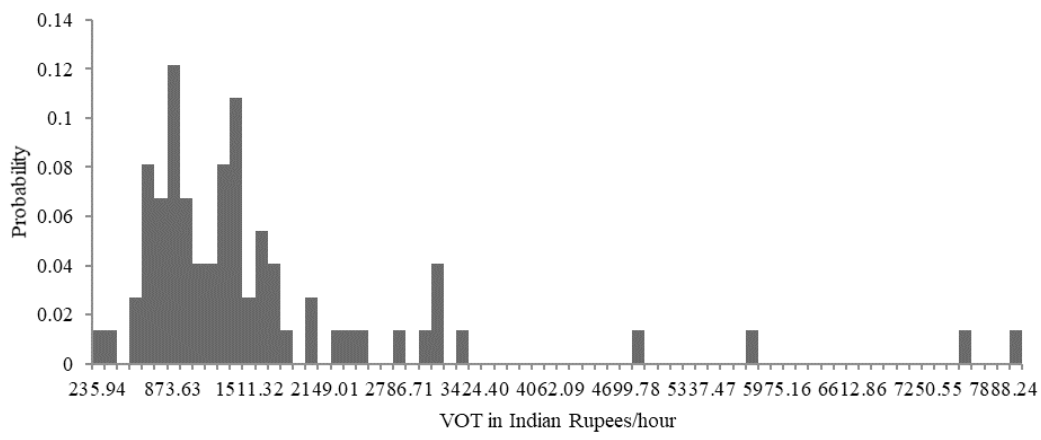

Fig. 6.

Histogram of VOT of 4-6 Axle Vehicles 


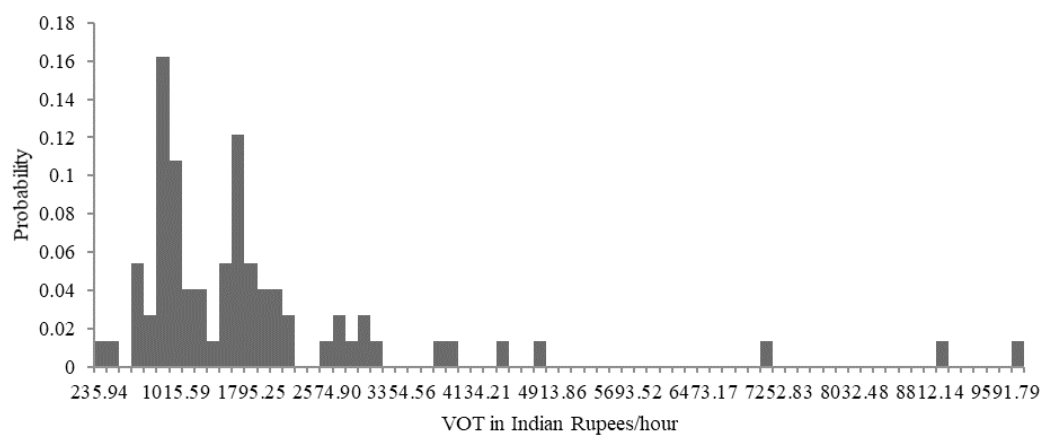

Fig. 7.

Histogram of VOT of Heavy Construction Machinery/Earth Moving Equipment

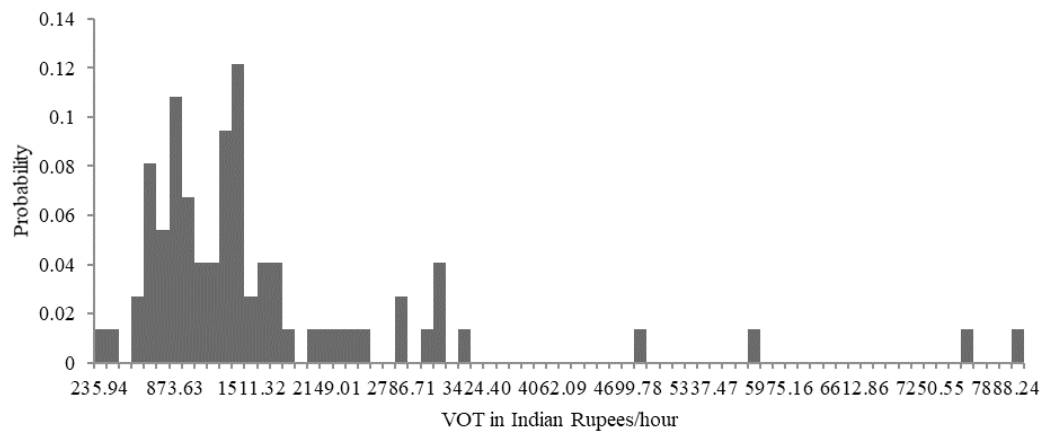

Fig. 8.

Histogram of VOT of Heavy Construction Machinery/ Earth Moving Equipment

\section{Discussion of Results}

How do the results compare with the extant studies in the context of India? In the case of Zirakpur - Parwanoo Expressway, the value of per hour of Travel-Time Savings was found to be 0.40 Euro/hour (equivalent to 29 Rupees/hour) for cars; 0.70 Euro/ hour (equivalent to 50 Rupees/hour) for light commercial vehicles; 1.40 Euro/hour (equivalent to $100 \mathrm{Rs} /$ hour) for trucks and buses; and 2.24 Euro/hour (equivalent to 160 Rupees /hour) for 3 to 6 axle trucks (IIDC, 2015). On the Ahmedabad to
Vadodara Expressway, the corresponding values were found to be 2.67 Euro/hour (equivalent to 190 Rupees /hour) for cars; 4.35 Euro/hour (equivalent to 310 Rupees/ hour) for light commercial vehicles; 8.9 Euro/hour (equivalent to 640 Rupees/ hour) for trucks/bus; and 14.18 Euro/hour (equivalent to 1010 Rupees/hour) for 4 to 6axle trucks (IIDC, 2015). The comparable values as obtained in this study are presented in Table2. However, it is important to note that these values only represent point estimates and hence are of limited practical use. In contrast, as presented in Table 3, it 
has been found that the VOT of toll road users follow positively skewed, log-Normal distributions. This finding is along the lines of Kawamura (2003) and Gupta \& Vadali (2008) who find that VOT tend to follow log-Normal distributions. For future studies related to traffic revenue risk assessment, these distributions are going to be useful compared to simple point estimates of VOT which is essentially a stochastic variable. The methodology developed in this paper can also be applied to other developing countries in the absence of primary data on VOT and WTP of potential toll road users.

\section{Conclusion}

This paper contributes to the literature in the following ways. First, there has been dearth of comprehensive study on estimation of VOT of toll road users in the context of India. This paper fills the gap by providing the VOT estimates for seven different toll road user categories.

Second, each of the seven user categories is found to be characterized by different VOT distributions. This user heterogeneity in terms of VOT is an important finding which needs to be considered while conducting revenue estimates and economic feasibility analysis of proposed toll roads. Third, simple point estimates of VOT have limited application in conducting toll road feasibility analysis. It is found that VOT of different user categories are positively skewed and follow LogNormal distribution. Since the economic feasibility of any toll road infrastructure project depends crucially on VOT and consequently WTP of potential toll road users, the estimated projections on VOT can prove to be useful in improving the revenue and toll forecasting in upcoming projects in the context of India.

\section{Acknowledgement}

The authors are grateful to Vasu Mohan Gupta for providing excellent support during the data collection phase of this project.

\section{References}

Athira, I. C.; Muneera, C. P.; Krishnamurthy, K.; Anjaneyulu, M. V. L. R. 2016. Estimation of Value of Travel Time for Work Trips, Transportation Research Procedia 17: $116-23$.

Bagui, S.K.; Ghosh, A. 2012. Traffic and Revenue Forecast at Risk for a BOT Road Project, KSCE Journal of Civil Engineering 16(6): 905-912.

Bain, R. 2009. Error and optimism bias in toll road traffic forecasts, Transportation 36(5): 469-482.

Ben-Akiva, M.; Bolduc, D.; Bradley, M. 1993. Estimation of travel choice models with randomly distributed value of time, Transportation Research Record, 1413: 88-97.

Boyer, K.D. 1997. Principles of Transportation Economics. Addison-Wesley Publishing Company. 416 p.

Brownstone, D.; Small, K. A. 2005. Valuing time and reliability: assessing the evidence from road pricing demonstrations, Transportation Research Part A: Policy and Practice 39(4): 279-93.

Gupta, R.S; Vadali, S.R. 2008. Stochastic Dominance Approach to evaluate Optimism Bias in Truck-Toll Forecasts, Transportation Research Record 2066(1): 98-105.

Hensher, D.A. 2001. Measurement of the Valuation of Travel Time Savings, Journal of Transport Economics and Policy 35(1): 71-98.

Hensher, D.A.; Goodwin, P. 2004. Using values of travel time savings for toll roads: avoiding some common errors, Transport Policy 11(2): 171-81. 
Hensher, D.A.; Ho, C.Q.; Liu, W. 2016. How much is too much for tolled road users: Toll saturation and the implications for car commuting value of travel time savings?, Transportation Research Part A: Policy and Practice 94: 604-621.

IIDC. 2015. The Purvanchal Expressway Project: Traffic, Toll and Financial Studies. IIDC Ltd. Available from Internet: <http://upeida.in>.

IRC. 2009. Manual on Economic Evaluation of Highway Projects in India, IRC Special Publication SP-30, Indian Road Congress. $351 \mathrm{p}$.

Iyer, K.C.; Sagheer, M. 2011. A real options based traffic risk mitigation model for build-operate-transfer highway projects in India, Construction Management and Economics 29(8): 771-779.

Kawamura, K. 2003. Perceived Benefits of Congestion Pricing for Trucks, Transportation Research Record 1833(1): 59-65.

Ku, S; An, H.K. 2020. Revenue Risk Evaluation for PPP Road Infrastructure, International Journal for Traffic and Transport Engineering 10(2): 187-198.

MORTH. 2020. Ministry of Road Transport and Highways. Available from Internet: <https://morth. nic.in/road-transport $>$.
NCHRP. 2006. Synthesis 364: Estimating Toll Road Demand and Revenue, A Synthesis of Highway Practice. Transportation Research Board, Washington, D.C. 105 p.

NHAI. 2020. Available from Internet: <http://tis. nhai.gov.in $>$.

Seetharaman, G. 2012. Untolled woe. Business Today. Available from Internet: <https://www.businesstoday. in $>$.

Singh, L.B.; Kalidindi, S.N. 2006. Traffic Revenue Risk Management through Annuity Model of PPP, International Journal of Project Management 24(7): 605-613.

Small, K.A. 2012. Valuation of travel time, Economics of Transportation 1(1-2): 2-14.

Toledo, T.; Sharif, S. 2019. The effect of information on drivers' toll lane choices and travel times expectations, Transportation Research Part F: Traffic Psychology and Behaviour 62: 149-59.

Yang, H.; Tang, W. H.; Cheung, W. M.; Meng, Q. 2002. Profitability and Welfare Gain of Private Toll Roads in a Network with Heterogeneous Users, Transportation Research, Part A: Policy and Practice 36(6): 537-554. 